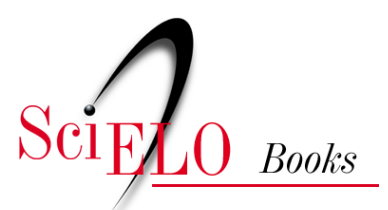

EDITORA

\title{
Capítulo 3. Cidades novas e o lugar
}

\author{
Ricardo Trevisan
}

\section{SciELO Books / SciELO Livros / SciELO Libros}

TREVISA, R. Cidades novas e o lugar. In: Cidades novas [online]. Brasília: Editora UnB, 2020, pp. 151-165. Pesquisa, inovação \& ousadia series. ISBN: 978-65-5846-158-6. https://doi.org/10.7476/9786558461586.0008.

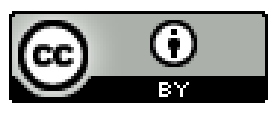

All the contents of this work, except where otherwise noted, is licensed under a $\underline{\text { Creative }}$ Commons Attribution 4.0 International license.

Todo o conteúdo deste trabalho, exceto quando houver ressalva, é publicado sob a licença Creative Commons Atribição 4.0.

Todo el contenido de esta obra, excepto donde se indique lo contrario, está bajo licencia de la licencia Creative Commons Reconocimento 4.0. 


\section{Cidades novas e o lugar}

Terceira parada: Nova Iorque, no Maranhão; Nova Petrolândia, em Pernambuco; Nova Ponte, em Minas Gerais; e Nova Jaguaribara, no Ceará.

Colete salva-vidas vestidos? Zarpamos em nossa embarcação rumo às próximas CNs. Quatro CNs unidas por um mesmo elemento: a água. Um volume colossal d’água represado por barreiras de concreto, dando origem a enormes reservatórios para gerar energia ou para minimizar a seca no agreste. Lagoas que escondem, em suas profundezas, cidades afogadas. Cidades um dia espontâneas, hoje submersas, fisicamente realocadas para sítios mais altos. Cidades rapidamente construídas para reassentar os moradores órfãos das cidades locadas na baixa.

CNs realocadas, como a brasileiríssima Nova Iorque, situada no estado do Maranhão, a 496 quilômetros de São Luís. Povoado nascido da pecuária itinerante do século XVIII permaneceu, até 1871, com o nome de Vila Nova. A partir daí, passou a ser chamado de Nova Iorque - homenagem feita pelo engenheiro norte-americano Edward Burnett, responsável por realizar, na época, estudos de transporte hidroviário no rio Parnaíba.

Mesmo rio que, nos anos 1960, recebeu a barragem para a instalação da usina da Companhia Hidroelétrica da Boa Esperança (Cohebe). O represamento do Parnaíba afetava diretamente Nova Iorque e Guadalupe, cidade vizinha situada no estado de Piauí: duas cidades que foram inundadas pelas águas represadas e tiveram de ser reconstruídas em sítios protegidos (HOLANDA, 2003).

Em ambos os casos, a nova cidade contou com um plano urbanístico e arquitetônico, sendo a CN de Nova Iorque projetada por uma equipe interna da Cohebe, e a CN Guadalupe pelo escritório carioca Wit-Olaf Prochnik - Arquitetura e Planejamento. Diferentemente de Guadalupe, cujo projeto proposto em 1963 
destoava pela adoção de conceitos modernistas, como a unidade de vizinhança, a nova Nova Iorque foi concebida mediante um pré-estudo cuidadoso de aspectos socioespaciais que compunham a antiga cidade, visando a um plano contextualizado sem necessariamente repeti-la ipsis litteris.

O agenciamento espacial na CN procurou seguir padrões já presentes e comuns aos cerca de 780 cidadãos nova iorquenses. As principais funções igreja e mercado - foram trabalhadas e implantadas a fim de potencializar a urbanidade presente no antigo vilarejo, enquanto outros aspectos foram requalificados: quadras e praças maiores, vias e calçadas mais largas, eixos diagonais para potencializar perspectivas, casas isoladas no lote (artifício desprezado com o desenvolvimento da nova urbe, a favor de antigos hábitos). Cuidados que buscavam evitar espaços segregacionistas e espaços cegos (HOLANDA, 2003), como ruas sem saídas e unidades fechadas. O projeto começou a ser implantado em 1966, prosseguindo por dois anos até sua inauguração em 1968.

Do Maranhão a Pernambuco, chegamos a Nova Petrolândia, a 430 quilômetros de Recife, localizada às margens do rio Itaparica. Cidade formada na segunda metade do século XIX (1887) graças às investidas econômicas trazidas pela construção de uma ferrovia e um cais, feitas a pedido do imperador D. Pedro II em 1870. Em sua homenagem, a antiga Itaparica passou a se chamar Petrolândia.

Um século mais tarde, o desenvolvimento da região ganhava novo impulso. Com a construção da Usina Hidroelétrica de Itaparica, atual Luiz Gonzaga, empreendida pela Companhia Hidro Elétrica do São Francisco (Chesf), uma área de 834 km² foi inundada, acumulando cerca de 11 bilhões de $\mathrm{m}^{3}$ de água, conformando o lago de Itaparica. A grande construção atraiu mão de obra, operários vindos de diversas regiões, aglomerada em acampamentos improvisados na vila de Jatobá. Porém, tal modificação da paisagem também alterou a história de Petrolândia. ${ }^{1}$

1 Petrus, versão em latim para Pedro; land, do vocábulo germânico: terra, gerando Terra de Pedro. 
Figura 10: Petrolândia

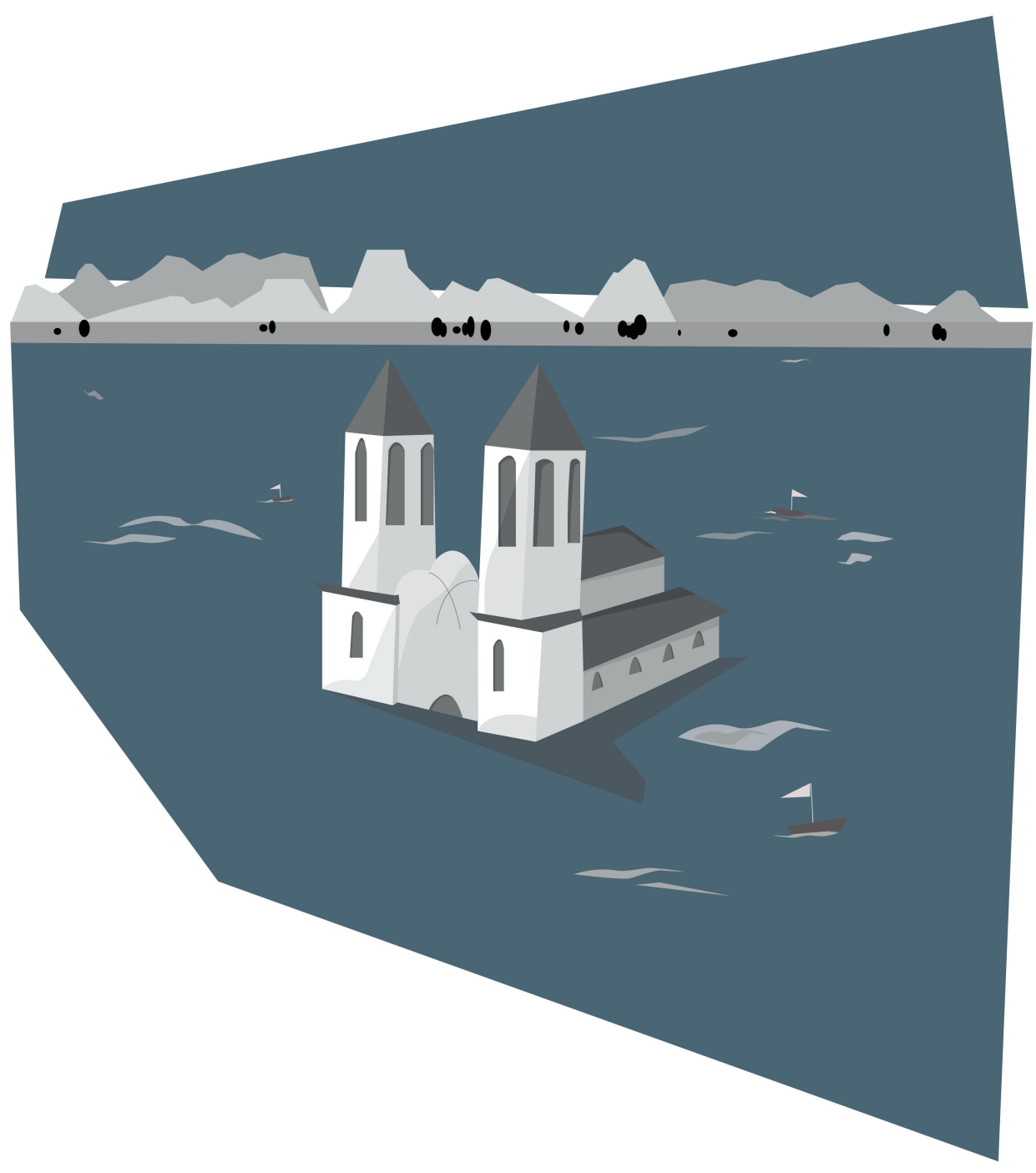


Em 1988, Petrolândia foi desapropriada pela Chesf, período no qual grande parte do antigo município foi inundada, inclusive a própria cidade, obrigando toda a população a deslocar-se para uma área totalmente estranha e adversa. Além da CN de Nova Petrolândia, núcleos menores correspondentes a pequenos povoados foram remanejados, dando origem ao projeto Apolônio Sales e às Agrovilas I, II, III e IV.

Com cerca de 30 mil habitantes, o projeto urbanístico da Nova Petrolândia nome apenas de batismo, já que os moradores insistem em chamá-la apenas por Petrolândia - foi adequado ao terreno às margens do lago, situando a $\mathrm{CN}$ próxima à antiga. Um plano linear em “L”, formado por quadras retangulares, foi agenciado de modo que várias vias tivessem por visual o reservatório, favorecido pelo declive natural do terreno. Rede de abastecimento de água, coleta e tratamento de esgoto e vias asfaltadas foram benefícios antes desconhecidos pela população petrolandense e adquiridos com a nova cidade projetada por profissionais da própria Chesf.

De Pernambuco ao Triângulo Mineiro, caso similar ocorreu na cidade de Nova Ponte (município fundado em 1938), quando seus moradores também foram remanejados para uma nova cidade a três quilômetros da antiga. O processo foi iniciado nos anos 1970, após desapropriação de terras feita pelas Centrais Elétricas de Minas Gerais (Cemig) para a instalação da Usina Hidrelétrica de Nova Ponte, inaugurada em 1982.

Assim como Nova Iorque (MA), em Nova Ponte houve um envolvimento da população no projeto da nova cidade, que se mostrou “ativa na articulação e construção de espaços públicos” (GRUPO HABURB, 2003, s.p.), garantindo, dentre as inúmeras ações, a transferência integral da antiga igreja, tijolo por tijolo.

O plano urbanístico foi realizado por uma equipe da Cemig, prevendo 9 mil habitantes e tendo por conceito projetual a referência ao traçado de cidades do interior - uma avenida principal que cruzaria toda a cidade. A proposta inicial de unificar o novo núcleo - fragmentado em sua origem pelo rio Araguari - foi logo revogada. A pedido da própria população, essa ideia passou por reformulações e as atividades foram locadas conforme as mesmas disposições dos bairros antigos. No total, seis avenidas e 23 ruas asfaltadas foram traçadas, conformando quadras e lotes - sem a 
presença dos quintais avantajados como eram na cidade original -, ocupados segundo um zoneamento primário (residencial, comercial, industrial, lazer etc.), servidos por uma rede de infraestrutura completa (energia, água, esgoto, telefone, iluminação pública etc.). O paisagismo foi contemplado nos canteiros centrais das avenidas, nas praças da igreja e da prefeitura e, principalmente, junto à orla do lago.

Embora todo o processo tenha sido iniciado na década de 1970, a ocupação só se efetivou no início dos anos 1990.

Do Triângulo Mineiro ao Ceará, encontramos Nova Jaguaribara, a 323 quilômetros de Fortaleza, banhada pelo rio Jaguaribe. Diferentemente das três CNs anteriores, o motivo da realocação da sede do antigo município cearense (1694) ocorreu não para o favorecimento da produção de energia, mas para garantir o abastecimento de água das populações do Vale do Jaguaribe. Ao favorecer habitantes afetados por longos períodos de estiagem, característica natural do semiárido nordestino, a barragem do rio e a criação do Açude do Castanhão garantiriam, segundo expectativas, o fornecimento de água em épocas de seca e controlariam possíveis enchentes em tempos de chuvas intensas.

Um debate construído ao longo do século XX, partindo dos primeiros estudos para o projeto do “Açude Público Castanhão”, realizados em 1910 pela Inspetoria de Obras Contra as Secas (Iocs) - atual Departamento Nacional de Obras Contra as Secas (Dnocs) -, até chegar à inauguração da nova cidade, em 25 de setembro de 2001 (PEROTE, 2006).

Todo o processo para efetivação do Açude ocorreu a partir de 1986, com a licitação para a construção da barragem, a verificação dos impactos e a transferência dos povoados afetados, principalmente Jaguaribara, o maior deles, com 4,5 mil pessoas - processo comandado pelo Dnocs em parceria com o governo do estado do Ceará e inserido no Programa de Irrigação do Nordeste (Proine).

A área escolhida para o novo núcleo ficava a 50 quilômetros da antiga Jaguaribara, situando-se às margens do lago artificial, no cruzamento entre duas vias importantes: uma de acesso à BR-116 e outra de acesso ao Açude Castanhão. 
O projeto urbanístico e arquitetônico ficou a cargo da Secretaria de Infraestrutura do Estado do Ceará (Seinfra), tendo por metodologia o planejamento participativo, envolvendo os trabalhos de uma equipe de sociólogos e assistentes sociais, um grupo de projetistas e técnicos em construção (urbanistas, arquitetos, engenheiros, agrônomos, botânicos, geógrafos e paisagistas), além da própria população (GRUPO HABURB, 2003).

A Nova Jaguaribara configura-se por uma malha urbana retangular, com quadras e lotes padrões, sendo traçada sobre o terreno escolhido e com dimensões para atender a 8 mil moradores. Duas vias estruturais definem todo o sistema viário e direcionam o crescimento ordenado da cidade. Seu espaço foi setorizado em zonas definidas - centro cívico (sedes administrativas e igreja); área residencial; áreas comerciais (atacadista e varejista); área de preservação ambiental; área de potencial turístico (na orla do Castanhão) e um distrito agroindustrial -, todas devidamente assistidas por infraestrutura, incluindo aterro sanitário e estação de tratamento de esgoto.

O projeto foi concluído em janeiro de 2001, com sua população reassentada nos meses de julho e agosto do mesmo ano. Detalhe, os mortos foram os primeiros a habitarem a nova cidade, com a inauguração do cemitério em 18 de julho de 2001.

Do Ceará, chegamos a outras regiões do país nas quais o processo de realocação de cidades também aconteceu: Aripuanã, em Mato Grosso (1966); Igaratá, em São Paulo (1969); Pilão Arcado (1974), Casa Nova (1976), Sento Sé (1976), Remanso (1976) e Sobradinho (1976), todas na Bahia; São Simão, em Goiás (1977); Canindé do São Francisco, em Sergipe (1987); e Itá, em Santa Catarina (1996).

CNs tão distantes; CNs tão próximas. Distantes no espaço; próximas pelas circunstâncias: uma segunda fundação. Cidades surgidas para ocupar o espaço funcional, e não físico - de suas homônimas alagadas permanentemente por águas fluviais represadas. Cidades que precisam do tempo e das relações sociais para readquirir uma identidade presente apenas na memória dos moradores e relacionadas a um espaço, agora, inabitável. Cidades afogadas, cidades mortas, que deram origem a CNs em sítios estrategicamente escolhidos para novas realidades. 
Assim, o sítio, ao lado do empreendedor e da função, favorece o nascimento de uma cidade, sendo o terceiro segmento a compor o DNA das CNs: um elemento importante no processo de construção de novos núcleos, podendo ser ele o responsável por despertar no(s) empreendedor(es) o desejo em criá-los ou o fator decisivo na definição de sua função, como veremos na sequência.

\subsection{Sítio: o lócus como gerador de cidades novas}

Para os historiadores Camille Vallaux e Jean Brunhes, em La Géographie de l'Histoire, cidade natural e cidade artificial se diferenciam pelos sítios onde se localizam. A formação urbana da cidade natural foi "espontaneamente determinada pela ação de fatores naturais, tais como cruzamento de vias de comunicação, estuários, baías, vales ou planaltos de fácil acesso, e pelo afluxo de população e da vida econômica que é consequência daquela ação” (apud PENNA, 1958, p. 10-11). Por sua vez, a cidade artificial surgiu ex nihilo, “onde não existia antes qualquer habitação ou, pelo menos, qualquer formação urbana suficientemente desenvolvida para servir aos propósitos” de seu idealizador. ${ }^{2}$ Contudo, discordo dos historiadores por desconsiderarem o sítio como elemento tão importante para a formação das cidades artificiais como o foi para as cidades naturais.

$\mathrm{O}$ alto de uma colina; a proximidade a um rio, a um lago ou ao mar; a presença de jazidas minerais ou águas termais; uma planície extensa; o encontro de terras produtivas; uma baía resguardada; a centralidade de um território; as fronteiras de um país etc. - esses são alguns dos aspectos geográficos, próprios da natureza ou confeccionados pelo homem, que definem a localização de cidades: variantes concernentes a um determinado sítio que nos permitem compreender, em parte, o surgimento de cada CN.

2 Constata-se que Letchworth, a primeira cidade-jardim inglesa, foi implantada sobre um antigo povoado, respeitando antigos percursos e preservando alguns edifícios. As villes nouvelles parisienses foram implantadas sobre áreas de várias comunas (SUDOUR, 1987). Na Hungria, as CNs empresariais surgiram em sítios ocupados por pequenos núcleos (HUNGARY, 1984). Esses são dados que certificam a afirmação de Camille Vallaux e Jean Brunhes. 
O sítio geográfico de uma cidade, seja ela de fundação natural ou artificial, refere-se a aspectos intrínsecos ao local e às suas áreas circunvizinhas, como: relevo, solo, clima e vegetação. O sítio "diz respeito a uma ou mais particularidades do lugar onde se encontra a cidade” (PELLETIER; DELFANTE, 2000, p. 15, tradução nossa). ${ }^{3}$ Opõe-se, portanto, à noção de situação geográfica - uma escala mais ampla de apreensão do território -, colocada por Fábio de Macedo Soares Guimarães, na qual a relação é dada entre a cidade e “outras áreas distintas, próximas ou distantes; não apenas geometricamente, mas com referência a acidentes geográficos, rios, fronteiras, cidades, vias, tendo em vista facilidades ou dificuldades de comunicações, de intercâmbio econômico etc.” (apud PENNA, 1958, p. 10).

Precisamente, as particularidades do sítio provêm de fatos: geológicos (presença de recursos minerais, estabilidade do solo); morfológicos (configuração do relevo); fenômenos climáticos (temperatura, índice pluviométrico, qualidade do ar); hidrológicos (águas de superfície e subterrânea); além da vegetação. São componentes que podem ser modificados conforme as necessidades humanas e, com isso, transformarem-se naquilo que denominamos de sítio criado - uma porção homogênea de espaço construído a fim de assistir necessidades não contempladas pelo sítio natural - por exemplo: muralhas, pôlderes holandeses, parques, aterros, represas, túneis etc.

Cada sítio é único e cada cidade não tem sentido fora do território onde está inserida (PANERAI et al., 1985). Para obtermos uma visão integral do tipo urbanístico em questão, é necessário olhar além do tecido urbano projetado. Devemos olhar para o sítio sobre o qual as CNs foram construídas, atentando para os fatores que contribuíram para sua fundação. Como salientou Philippe Panerai, o sítio "pré-existe à urbanização e mantém-se sob ela”, habilitando-nos de “nele ‘reconhecer’ os pontos singulares, ler os conjuntos, determinar os limites” e, por que não, entender sua história (PANERAI, 2006, p. 48).

Se o fundador de uma CN, devido ao caráter global de sua função dirigente, tem a atenção voltada para as grandes linhas estratégicas do processo, nem por isso deverá

3 “[...] fait référence à une ou plusieurs particularités du lieu où est située la ville.” 
menosprezar as características táticas do sítio em que pretende instalar seu empreendimento. As considerações de topografia, de abastecimento d’água, clima, paisagem, proximidade de zonas agrícolas e áreas para obtenção de materiais de construção sempre foram levadas em conta, desde a mais alta antiguidade até dias recentes.

Tomemos por exemplo o Brasil Colônia. Os portugueses, quando aqui chegaram, escolheram como sítio estratégico para locação de suas CNs administrativas e de defesa territorial as colinas à beira-mar. Direcionada pelas “Cartas Régias” - determinações gerais nas quais havia normas para localização das aglomerações e para seus planos urbanísticos (SANTOS, 1968) -, a opção de sítios elevados na costa brasileira e sua respectiva urbanização se concretizou com respaldo no conhecimento técnico lusitano, adquirido ao longo de séculos no velho continente.

Ao optar por um terreno irregular e mais alto, como no caso de Olinda, os patrícios se diferenciaram dos holandeses, exploradores aqui presentes durante o domínio espanhol sobre Portugal (1580-1640). Ao conquistarem essa região da capitania de Pernambuco, os holandeses desprezaram Olinda - incendiando-a -, e se apossaram de uma área alagadiça - típica nos Países Baixos -, ao lado da pequena Recife, onde projetaram a CN de Maurícia - uma escolha de sítio feita conforme o substrato técnico (repertório urbanístico) de cada cultura: as colinas para atender aos interesses defensivos dos portugueses; os mangues para implantar uma nova civilização dos holandeses, além de servir como porta de entrada para o interior da região, rio como via de penetração.

São vantagens e desvantagens do sítio, dependentes de um saber-fazer cidades, influenciadas igualmente pelas condicionantes de um determinado momento. Sítios considerados estratégicos num momento inicial (defesa), após inovações tecnológicas (técnicas bélicas) ou mudanças de fronteiras (conquista de territórios), passam a ser irrelevantes. Sítios economicamente importantes (reservas minerais) veem suas cidades morrerem após algumas décadas (esgotamento das jazidas), como ocorreu com as CNs de Montdauphin e Arc-en-Senans na França (LACAZE, 1994). 
Embora tais variações possam vir a acontecer, dificilmente locais artificialmente escolhidos apresentarão condições de sítio desfavoráveis, salvo pressa, erro ou predominância momentânea de fatores políticos prementes. A CN de Tucumã (1981), no Pará, por exemplo, surgiu após estudos geológicos do Instituto Nacional de Colonização e Reforma Agrária (Incra) e da Superintendência de Desenvolvimento da Amazônia (Sudam), que detectaram áreas da floresta amazônica possuidoras de terras produtivas (terra roxa) para a implantação de fronteiras agrícolas (ARRUDA, 2009).

Num contexto mais amplo, as posições das introduced capitals foram por demais estudadas, não sendo reflexo das emoções e desejos momentâneos. A localização para uma nova capital na hinterlândia brasileira, como sabemos, antecedeu em muito o período JK (1955-1960), tendo sido especulada no período pombalino (1750-1780) e selecionada pela Missão Cruls entre 1892 e $1894 .{ }^{4}$ O sítio do novo Distrito Federal foi determinante no assentamento fronteiriço, buscando "vigorar e dispersar a razão de ser brasileira e promover as necessidades de uma economia periférica” (BEST; YOUNG, 1972, p. 1044, tradução nossa). ${ }^{5}$

Portanto, ao selecionar um sítio para se implantar uma CN, seu empreendedor (público ou privado) não age ao seu bel-prazer, levado pelo imediatismo. Todo terreno de uma CN é minuciosamente explorado, estudado e planejado para que a adição de um assentamento urbano traga os resultados esperados. Tal levantamento ambiental prévio e respectiva sistematização de dados geográficos contraídos atribuem, segundo Gilles Leloup (1983), uma nova conceituação ao local escolhido: sítio pré-determinado, denominação adotada na língua francesa como site obligé - sítio obrigado, forçado, precisado, escolhido (FRANCE, 1975).

4 Comissão Exploradora do Planalto Central criada pelo governo do presidente Floriano Peixoto em 9 de junho de 1892, sendo chefiada pelo diretor do Observatório Nacional, Luiz Cruls, e composta por técnicos e cientistas diversos. O objetivo de tal Comissão era selecionar e demarcar a área do novo Distrito Federal na região central do país.

5 “[...] to force and to disperse the Brazilian raison d'être and promote the needs of a peripheral economy." 
O sítio pré-determinado pode abranger uma pequena parcela de terra (CNs balneárias) ou um amplo território (CNs de expansão e ocupação territorial). O agente definidor da escala será a função dominante, construída pelas características do próprio sítio e os interesses do(s) empreendedor(es).

Numa escala territorial, destaca-se o programa político australiano de 1972, que buscou descentralizar a ocupação do país por meio da implantação de CNs em regiões desabitadas. Planejadores mais animados propunham a locação de novos assentamentos em áreas inóspitas - terras isoladas "pela distância, aridez, escassez de água, condições extremas de clima ou pela terra não propícia à agricultura” (RUSHMAN, 1976, p. 12, tradução nossa) ${ }^{6}$-, as quais caracterizam grande parte do território australiano.

“Terras virgens” onde, segundo Anatole Kopp (apud MERLIN, 1975, p. 10), 40\% das cidades socialistas foram implantadas na URSS - o restante se concentrou ao redor de grandes centros urbanos como cidades-satélites, as “cidades-sputniks”, a fim de promover o desenvolvimento industrial. Além de agrupar $1 / 4$ da população daquela nação, essa ação de tomada do território pelas CNs foi tida pelo arquiteto e urbanista como o principal meio de valorização das terras antes desocupadas.

Por sua vez, a ocupação do território nos Estados Unidos da América ficou sob a responsabilidade do agente privado, também responsável por escolher o sítio das new communities, definindo seu tamanho e suas infraestruturas. Com isso, as CNs norte-americanas são caracterizadas por sítios definidos pela oferta e especulação de terrenos disponíveis; por uma escala prevista sempre ambiciosa, mas dependente do mercado; e pela localização próxima a uma rodovia não saturada. Fruto do liberalismo americano, “a falta de discernimento na localização dos sítios

6 "[...] by distance, aridity, water scarcity, extreme weather conditions or by land not suitable to agriculture.” 
é um dos pontos fracos das CNs americanas”, como aponta Jean-Paul Loevenbruck (1986, p.II, tradução nossa). ${ }^{7}$

Já em regiões urbanizadas, as cidades-satélites tiveram seus sítios pré-determinados em consonância aos interesses de políticas desenvolvimentistas. As villes nouvelles surgiram planejadas num contexto de reestruturação da área metropolitana das grandes cidades, isto é, um planejamento do território defendido pela Assembleia Nacional francesa em 1963, cujo objetivo era combater o crescimento do desequilíbrio econômico e demográfico nas regiões (AHTIK, 1969). Para isso, novos nós foram criados na armadura urbana de Paris, Lion, Marselha e Lille, com CNs isoladas geograficamente da cidade-mãe - seja por um cinturão verde, um lago ou por condições topográficas -, porém interligadas por um eixo de comunicação rápida (rodovia ou ferrovia).

Para conseguir uma equilibrada condição de desenvolvimento social e econômico e o controle do crescimento das grandes cidades, a criação de cidades-satélites a uma distância razoável da cidade-mãe sempre foi recomendável (IRAN, 1991). Geograficamente, os princípios gerais levados em conta para a localização das CNs satélites devem compreender: características dos limites urbanos existentes; localização para absorver a população excedente da região metropolitana; condições territoriais e ecológicas da área a ser afetada; estudo das condições do solo; fornecimento de água; drenagem de águas e sistema de esgoto; impacto das indústrias etc. Em vários países, a seleção de sítios próximos a cidades grandes seguiu a mesma receita, com maior ou menor cuidado, das new towns de Londres às cidades-satélites ao redor do Plano Piloto em Brasília.

Além de uma visão geral sobre o território ou sobre uma região urbanizada, sítios foram pontualmente escolhidos em áreas desocupadas, particularmente para a criação de polos industriais. Sediaram a transferência de indústrias existentes em regiões congestionadas, como ocorrido na Índia (PRAKASH, 1969), ou deram início a uma industrialização a partir da exploração de recursos naturais encontrados,

7 “[...] manque de discernement dans la localisation des sites est l'une des faiblesses des villes nouvelles américaines." 
fossem recursos hídricos para construção de hidrelétricas, fossem recursos minerais para captação de matéria-prima. Cada qual corroborando para o surgimento de CNs.

Ainda há CNs nascidas em sítio pré-determinado ou au site obligé, em função da exploração econômica dos recursos naturais nele encontrados. Nascidas também pela ausência de núcleos urbanos próximos para fornecer mão de obra; geradas pela necessidade em criar condições de habitabilidade a seus futuros moradores. Foi assim com as dezenas de cidades empresariais criadas no continente africano, dentre elas: Kafue e suas indústrias químicas na Zâmbia, Zouérate e suas minas de ferro na Mauritânia e Lubumbashi e suas minas de cobre no Zaire. Uma multiplicação de CNs em países em desenvolvimento, verificada nos últimos 70 anos, que traduzem o esforço de trazer à tona riquezas até então inexploradas. CNs cuja escolha do sítio foi “o primeiro problema a ser colocado” (MOUSSA, 1972, p. 8, tradução nossa). ${ }^{8}$

Do sítio escolhido ao sítio ocupado, podemos afirmar que o lócus é tão importante para a elaboração do projeto urbanístico como o é para a seleção do terreno da CN.

Quando queremos compreender uma cidade e seu plano urbanístico, e particularmente o caso de uma CN, a análise de sítio é indispensável. Um plano urbano é a expressão de toda a história de uma cidade e não a fotografia de um momento dado de sua evolução. Para Jean-Louis Huot, essa análise "pode começar por examinar o sítio (local exato onde se fez a implantação inicial) e a situação (posição da cidade em sua região)" (HUOT, 1988, p. 11, tradução nossa). ${ }^{9}$

Podemos dizer, portanto, que, na cidade artificial, o lócus escolhido expressa os objetivos precisos de seu fundador. Enquanto uma cidade natural nasce sobre o terreno, uma cidade artificial nasce no mapa e é, em seguida, transportada para o terreno. De praxe, uma CN é uma criação ex nihilo sobre um “sítio virgem”, consagrado outrora à atividade agrícola ou ainda intocado pelas mãos humanas.

8 “[...] le premier problème à poser."

9 "[...] pouvez commencer par examiner le site (emplacement exact où le déploiement initial a été effectué) et la situation (emplacement de la ville dans votre région)." 
No caso das bastides francesas, as estradas e caminhos existentes, curso de rio, possibilidade de um porto ou de uma ponte, construções presentes, disposição irregular do terreno, foram incorporados ao projeto (traçado). Os "procedimentos de agrimensura permitem os primeiros traços seguidos por um parcelamento e a implantação dos edifícios, que uma vez situados marcam o território por vários séculos” (PANERAI et al., 1985, p. 39, tradução nossa). ${ }^{10}$ Trata-se, portanto, de uma relação “natural” entre a CN e os elementos pré-existentes do local.

Uma relação rebatível a qualquer $\mathrm{CN}$, quando encontramos uma preocupação mínima em adequar o projeto ao seu terreno basal. Dessa concordância, nascem cidades implantadas em pontos estratégicos e traçadas conforme as condições do relevo - irregulares em terrenos acidentados e regulares em terrenos planos, salvo exceções.

Também são condicionantes naturais que irão influenciar os projetistas no momento de planejar a futura cidade: topos ou vales de terrenos destinados a áreas para locação do centro ou de parques; faixas verdes às margens de rios - os green fingers do paisagista norte-americano Frederick Law Olmsted (1822-1903) - protegendo os corpos fluviais, separando-os de áreas urbanas; elementos naturais incorporados no projeto de CNs, como em Cergy-Pontoise (França), uma ville nouvelle fundada num conceito de "paisagismo anfiteatro", ou Redditch (Inglaterra), onde os cursos d'águas pré-existentes foram mesclados ao projeto - diferentemente do processo de correção e drenagem usual -, sendo trabalhados de forma a quebrar a monotonia das moradias populares, ou de Adelaide (Austrália), cujo plano do coronel William Light (1786-1839) foi “concebido dentro de uma estética própria para vias, praças e parques-cinturões, implantados conforme o sítio, dando a essa cidade um caráter urbano distinto de outras cidades australianas” (THOMAS et al., 1982, p. 269, tradução nossa). ${ }^{11}$

10 "[...] les procédures d'arpentage permettent les premières traces suivies d'un morcellement et de l'implantation des bâtiments, qui autrefois localisés marquent le territoire depuis plusieurs siècles.”

11 “[...] conceived within a proper aesthetic for roads, squares and greenbelts, deployed according to the site, giving this city an urban character distinct from other Australian cities." 
Figura 11: Cergy-Pontoise

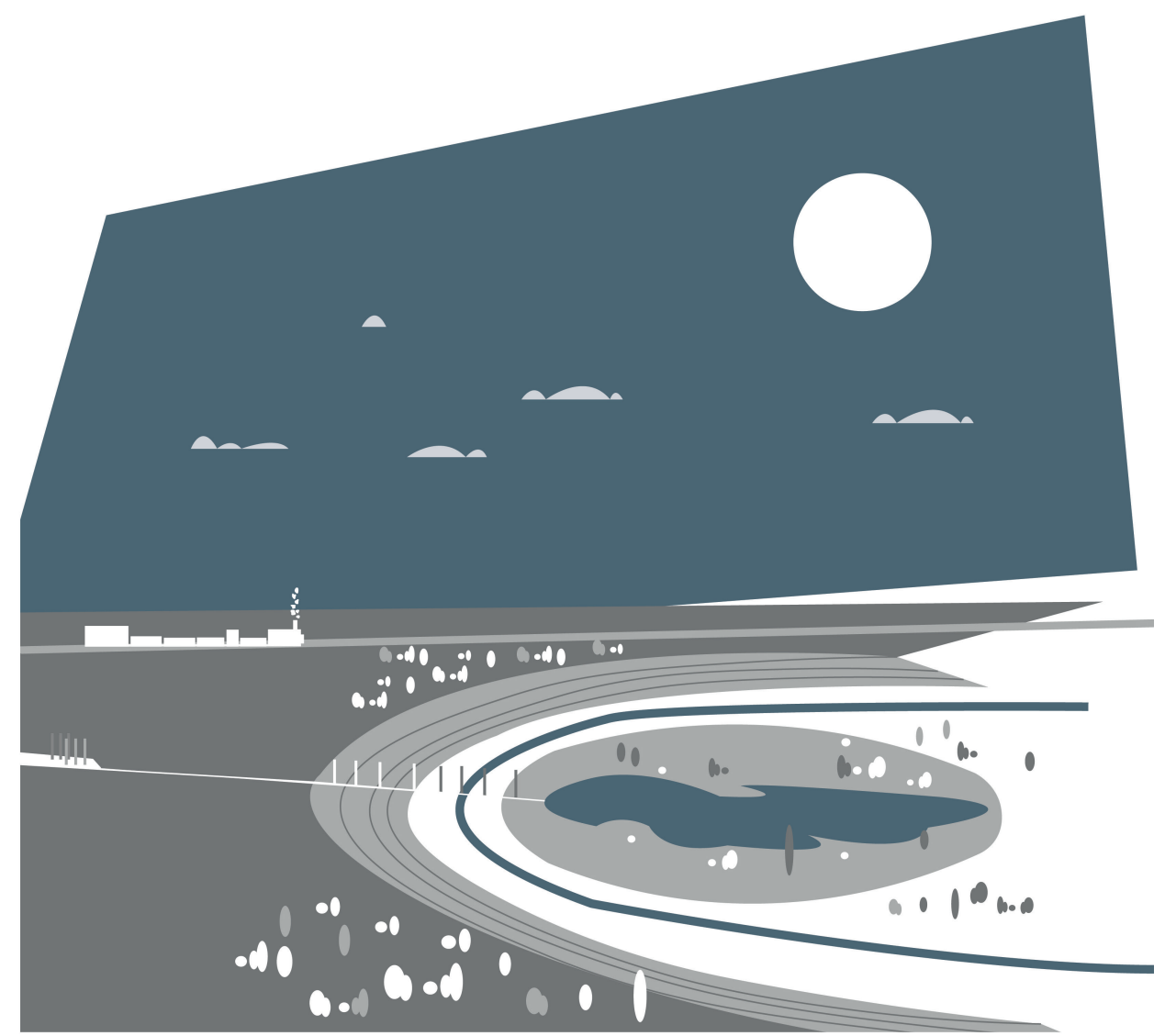

Portanto, o sítio é importante tanto na compreensão dos motivos que fomentaram o nascimento de CNs como também no entendimento dos projetos a elas atribuídos: um elemento muitas vezes despercebido - até mesmo negligenciado por estudiosos, mas de grande relevância para a construção de um conceito sobre CNs. Um pilar que, somado aos outros dois (desejo e necessidade), dará suporte para a materialização das CNs. Uma base de sustentação para que profissionais das mais diversas disciplinas possam elaborar seus projetos de acordo com as vontades de seu empreendedor e as características do sítio escolhido. 